\title{
Low BASDAl score alone is not a good predictor of anti-tumor necrosis factor treatment efficacy in ankylosing spondylitis: a retrospective cohort study
}

Bora Nam ${ }^{1 \dagger}$, Bon San Koo ${ }^{2 \dagger}$, Tae-Han Lee ${ }^{1}$, Ji-Hui Shin ${ }^{1}$, Jin-Ju Kim³ ${ }^{3}$ Seunghun Lee ${ }^{4}$, Kyung Bin Joo ${ }^{4}$ and Tae-Hwan Kim ${ }^{1 *}$

\begin{abstract}
Background: The purpose of this study was to determine the prevalence of high disease activity as measured using the Ankylosing Spondylitis Disease Activity Score (ASDAS) in ankylosing spondylitis (AS) patients who nonetheless have low Bath Ankylosing Spondylitis Disease Activity Index (BASDAl) scores after anti-tumor necrosis factor (TNF) treatment. Its clinical impact on anti-TNF survival was also investigated.

Methods: We conducted a single-centre retrospective cohort study of AS patients having low BASDAI scores $(<4)$ and available ASDAS-C-reactive protein (CRP) data after 3 months of first-line anti-TNF treatment. Patients were grouped into high-ASDAS $(\geq 2.1)$ and low-ASDAS $(<2.1)$ groups according to the ASDAS-CRP after 3 months of anti-TNF treatment. Their characteristics were compared. And survival analyses were carried out using Kaplan-Meier curves and log-rank test with the event being discontinuation of anti-TNF treatment due to lack/loss of efficacy.

Results: Among 116 AS patients with low BASDAl scores after 3 months of anti-TNF treatment, 38.8\% were grouped into the high-ASDAS group. The high-ASDAS group tended to have greater disease activity after 9 months of treatment (BASDAl $2.9 \pm 1.1$ vs. $2.3 \pm 1.4, p=0.007$; ASDAS-CRP $1.8 \pm 0.6$ vs. $1.5 \pm 0.7, p=0.079$; proportion of high ASDAS-CRP $27.8 \%$ vs. $13.8 \%, p=0.094$ ) and greater risk of discontinuing anti-TNF treatment due to lack/loss of efficacy than the low-ASDAS group ( $p=0.011$ ).

Conclusions: A relatively high proportion of AS patients with low BASDAI scores had high ASDAS-CRP. These lowBASDAI/high-ASDAS-CRP patients also had a greater risk for discontinuation of anti-TNF treatment due to low/lack of efficacy than the low-ASDAS group. The use of the ASDAS-CRP alone or in addition to the BASDAI may improve the assessment of AS patients treated with anti-TNF agents.
\end{abstract}

Keywords: Ankylosing spondylitis, Disease activity, Ankylosing spondylitis disease activity score (ASDAS), Bath Ankylosing spondylitis disease activity index (BASDAI), Anti-tumor necrosis factor (anti-TNF)

\footnotetext{
* Correspondence: thkim@hanyang.ac.kr

${ }^{\dagger}$ Bora Nam and Bon San Koo contributed to this work equally as first authors 1 Department of Rheumatology, Hanyang University Hospital for Rheumatic Diseases, 222-1 Wangsimni-ro, Seongdong-gu, Seoul 04763, Republic of Korea

Full list of author information is available at the end of the article
}

C C The Author(s). 2021 Open Access This article is licensed under a Creative Commons Attribution 4.0 International License, which permits use, sharing, adaptation, distribution and reproduction in any medium or format, as long as you give appropriate credit to the original author(s) and the source, provide a link to the Creative Commons licence, and indicate if changes were made. The images or other third party material in this article are included in the article's Creative Commons licence, unless indicated otherwise in a credit line to the material. If material is not included in the article's Creative Commons licence and your intended use is not permitted by statutory regulation or exceeds the permitted use, you will need to obtain permission directly from the copyright holder. To view a copy of this licence, visit http://creativecommons.org/licenses/by/4.0/. The Creative Commons Public Domain Dedication waiver (http://creativecommons.org/publicdomain/zero/1.0/) applies to the data made available in this article, unless otherwise stated in a credit line to the data. 


\section{Background}

Ankylosing spondylitis (AS) is characterised by inflammatory back pain which can lead to spinal structural damage. In addition, AS may also involve the peripheral joints, eyes, skin, and the intestinal systems. Nonsteroidal anti-inflammatory drugs are typically the primary treatment option for AS, although anti-tumor necrosis factor (anti-TNF) agents have emerged as a novel alternative treatment [1]. Unlike other diseases, the severity of AS disease cannot be assessed using simple or direct "gold standard" measures, as is the case for glycosylated haemoglobin in diabetes mellitus and blood pressure in hypertension, due to the range and complexity of AS symptoms [2]. Although, several attempts have been made to develop a novel biomarker of AS disease activity and some interesting biomarkers have been identified $[3,4]$, composite scoring systems, namely the Bath Ankylosing Spondylitis Disease Activity Index (BASDAI) and/or Ankylosing Spondylitis Disease Activity Score (ASDAS) have been mainly applied when assessing AS disease activity $[5,6]$.

The BASDAI contains six questions addressing fatigue, back pain, peripheral joint pain/swelling, enthesitis, and morning stiffness [5]. Similar to the BASDAI, the ASDA $\mathrm{S}$ includes self-reported indices of back pain, duration of morning stiffness, peripheral joint pain/swelling, and patient global assessment of disease activity; however, the ASDAS also includes laboratory test results, such as the C-reactive protein (CRP) or erythrocyte sedimentation rate (ESR), and each parameter is weighted, not simply added up as for the BASDAI [6]. Although ASDAS might be affected infections or conditions influencing inflammatory markers, the ASDAS has been considered more objective than the BASDAI and was recently recommended as the "target" scale for AS treatment $[7,8]$. Nevertheless, the BASDAI is still widely used because it is simpler and less time-consuming than the ASDAS. Moreover, the BASDAI is used to measure disease activity to initiate or maintain TNF inhibitor therapy in routine clinical practice and is a standard parameter when the cost of anti-TNF therapy for Korean AS patients is covered under the Korean National Health Insurance Service [9].

In some AS patients with low disease activity as measured by the BASDAI, the patient may nonetheless complain of pain or have elevated inflammatory markers. In these cases, assessing disease activity with other measurement tools such as the ASDAS can be helpful. In some such cases, we may find that some patients have both high ASDAS and low BASDAI scores at the same time.

Inaccurate measurement of disease activity can lead to inappropriate treatment and/or medication of AS patients. Therefore, the aim of this study was to determine the prevalence of high disease activity as measured using the ASDAS-CRP, in AS patients who nonetheless have low BASDAI scores after anti-TNF treatment. The clinical impact of this discordance in disease activity on anti-TNF survival was also investigated.

\section{Methods \\ Patient recruitment}

We conducted a retrospective cohort study of AS patients who began first-line anti-TNF treatment between January 2012 and December 2016 in a single tertiary referral hospital. All patients satisfied the 1984 modified New York criteria for the classification of AS [10]. Only patients having both BASDAI and ASDAS-CRP data available after 3 months ( 6 weeks for Infliximab) of antiTNF treatment were included. Patients with high BASDAI scores $(\geq 4)$ after 3 months ( 6 weeks for Infliximab) of anti-TNF treatment were excluded. Patients with other conditions affecting CRP, such as inflammatory bowel disease or infectious disease, were also excluded.

Enrolled patients were categorised into either the highASDAS (ASDAS-CRP $\geq 2.1$ ) or low-ASDAS (ASDASCRP <2.1) groups according to the ASDAS-CRP assessment completed after 3 months (6 weeks for infliximab) of anti-TNF treatment.

This study was performed according to the guidelines of the Helsinki Declaration and approved by the institutional review board of Hanyang University Hospital (IRB file No. HYUH 2019-09-016). Patient consent to participate was waived as this is a retrospective study.

\section{Data collection}

We obtained demographic (age and sex) and diseaserelated clinical data (disease duration [duration since first AS-specific symptoms], history of uveitis or psoriasis, peripheral joint involvement, human leukocyte antigen [HLA]-B27 positivity, and type of anti-TNF agent) by medical chart review. The serum concentration of CRP and ESR, BASDAI score, and ASDAS-CRP were obtained at 0 month, 3 months ( 6 weeks for Infliximab), and 9 months after initiation of anti-TNF treatment. In addition, radiographs obtained within 2 years of the index date were scored using the modified Stoke Ankylosing Spondylitis Spinal Score (mSASSS).

The index date was defined as the date on which the BASDAI and ASDAS-CRP were measured 3 months (6 weeks for Infliximab) after initiation of the first-line anti-TNF treatment. All enrolled patients were observed until the time of their last visit, discontinuation of antiTNF treatment, or December 2019.

The reason for discontinuation of anti-TNF treatment was collected as reported by the treating rheumatologist for the following pre-specified and mutually exclusive 
categories: clinical remission, lack/loss of efficacy, and adverse events.

\section{Statistical analyses}

The demographic and clinical characteristics of the patients were summarised in a descriptive analysis. To compare the characteristics of the high-ASDAS and lowASDAS groups, Student's t tests were used for normally distributed data or a Mann-Whitney $U$ test for nonnormally-distributed data was used for continuous variables; dichotomous variables were analysed using the Chi-square test.

Survival analyses were carried out using Kaplan-Meier curves with the event being discontinuation of anti-TNF treatment due to lack/loss of efficacy. Patients discontinuing anti-TNF treatment due to clinical remission or adverse events were not included in the statistical analyses. In addition, the survival curves of the two groups were compared using the log-rank test.

To identify possible risk factors associated with high ASDAS-CRP after 3 months (6 weeks for infliximab) of anti-TNF treatment, multivariable logistic regression analyses were completed. Variables with $p$-values $<0.2$ in the univariable model were advanced to the multivariable logistic regression models. In addition, age was retained as a parameter in the multivariable models.

All analyses were performed using $\mathrm{SPSS}^{\bullet}$ software (version 26.0; SPSS Inc., IL, USA). P-values $<0.05$ were considered statistically significant.

\section{Results}

Clinical characteristics of patients

A total of 116 AS patients were included in this study, with 41 patients receiving adalimumab, 34 etanercept, 27 infliximab, and 14 golimumab (Fig. 1). The demographic and clinical characteristics of the patients at enrolment are shown in Table 1 . The median age of the patients was $33.9(26.7-40.3)$ years and $94 \%$ were male. The median disease duration was 10.8 (5.3-15.5) years. With regard to disease activity, the mean BASDAI and ASDAS-CRP values were $2.3 \pm 0.9$ and $2.0 \pm 0.5$, and the median ESR and CRP concentration were 3.0 (2.06.0) $\mathrm{mm} / \mathrm{hr}$. and $0.2(0.2-0.2) \mathrm{mg} / \mathrm{dL}$, respectively. In addition, the median mSASSS was 9.0 (6.0-25.9).

During a median follow-up duration of 6.4 (4.5-7.1) years, 14 patients $(12.1 \%)$ discontinued their anti-TNF agents: 9 (69.2\%) due to lack/loss of efficacy, 3 (23.1\%) due to clinical remission, and 1 (7.7\%) due to an adverse event.

\section{Prevalence and characteristic of AS patients with high ASDAS-CRP after anti-TNF treatment}

Among the total patient population, $38.8 \%$ of the patients were categorised into the high-ASDAS group. The patients in the high-ASDAS group had significantly greater BASDAI scores $(3.0 \pm 0.6$ vs, $1.8 \pm 0.8, p<$ $0.001)$, ASDAS-CRP $(2.5 \pm 0.3$ vs. $1.7 \pm 0.2, p<0.001)$, and ESR $(5.0[2.0-11.5] \mathrm{mm} / \mathrm{hr}$. vs. $2.0[2.0-5.0] \mathrm{mm} /$ hr., $p=0.003$ ) measurements than those of the low-

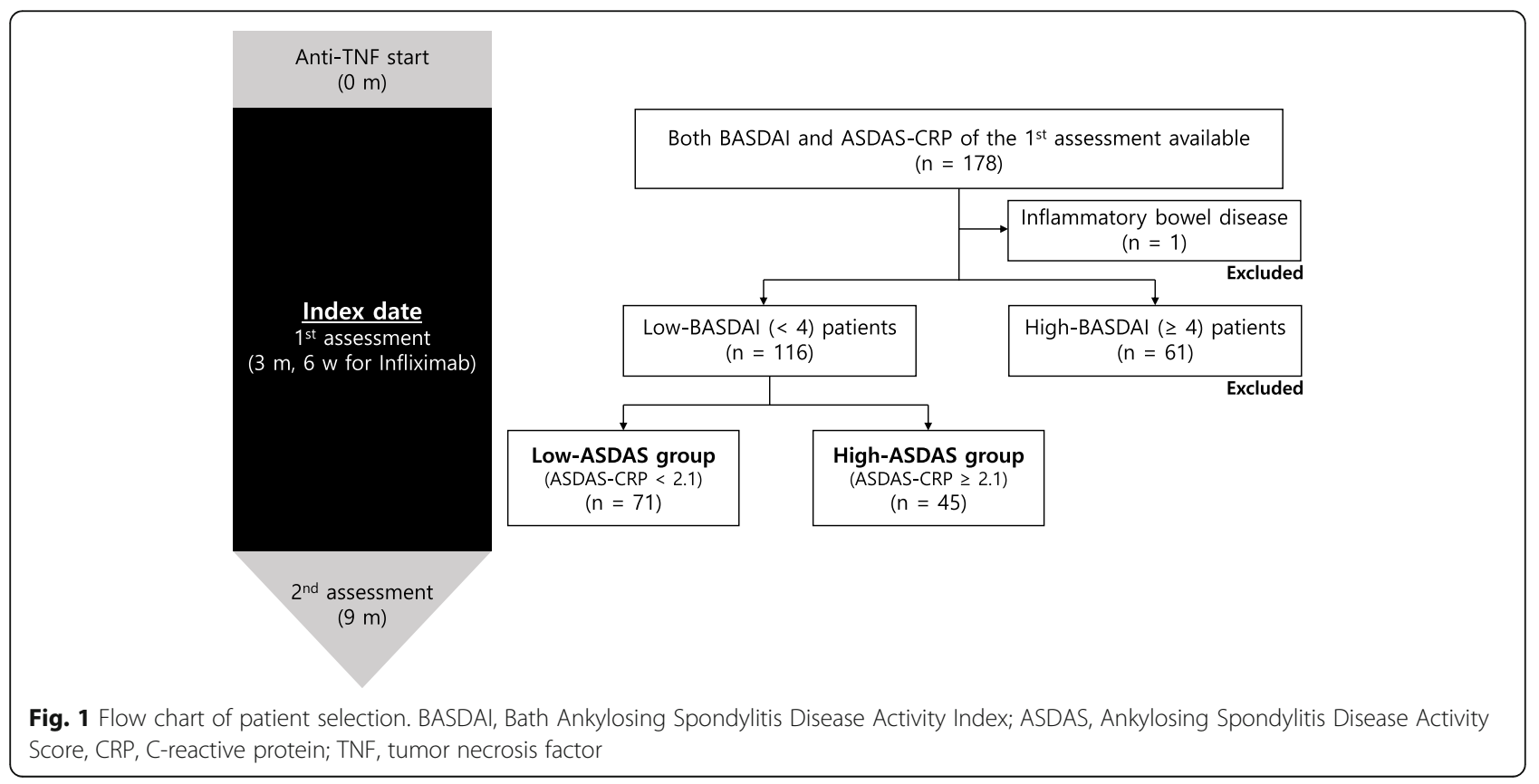


Table 1 Demographic characteristics of the study population

\begin{tabular}{ll}
\hline & $\begin{array}{l}\text { Variables } \\
(\boldsymbol{n}=116)\end{array}$ \\
\hline Age at enrolment, years & $33.9(26.7-40.3)$ \\
Male sex & $109(94)$ \\
Disease duration, years & $10.8(5.3-15.5)$ \\
Follow-up duration, years & $6.4(4.5-7.1)$ \\
HLA B27 positivity & $115(99.1)$ \\
Peripheral joint involvement & $52(44.8)$ \\
History of psoriasis & $2(1.7)$ \\
History of uveitis & $35(30.2)$ \\
mSASSS & $9.0(6.0-25.9)$ \\
BASDAI & $2.3 \pm 0.9$ \\
ASDAS-CRP & $2.0 \pm 0.5$ \\
High ASDAS-CRP $(\geq 2.1)$ & $45(38.8)$ \\
ESR, mm/hr. (normal $\leq 20)$ & $3.0(2.0-6.0)$ \\
CRP, mg/dL (normal $\leq 0.3)$ & $0.2(0.2-0.2)$ \\
Use of anti-TNF agents & \\
Adalimumab & $41(35.3)$ \\
Etanercept & $34(29.3)$ \\
Infliximab & $27(23.3)$ \\
Golimumab & $14(12.1)$ \\
Discontinuation of anti-TNF agent during follow up & $13(11.2)$ \\
Lack/loss of efficacy & $9(69.2)$ \\
Clinical remission & $3(23.1)$ \\
Adverse event & $1(7.7)$ \\
\hline &
\end{tabular}

Numerical quantitative data were presented as the "mean $\pm \mathrm{SD}$ " or "median $(\mathrm{IQR})$ " and categorical data were presented as the "frequency (\%)" $S D$ standard deviation, IQR interquartile range, HLA B27 human leukocyte antigen B27, mSASSS modified Stoke Ankylosing Spondylitis Spinal Score, BASDAI Bath Ankylosing Spondylitis Disease Activity Index, ASDAS Ankylosing Spondylitis Disease Activity Score, CRP C-reactive protein, ESR erythrocyte sedimentation rate, $T N F$ tumor necrosis factor

ASDAS group. The median CRP concentration was comparable between the two groups $(0.2[0.2-0.3] \mathrm{mg} /$ $\mathrm{dL}$ vs. $0.2[0.2-0.2] \mathrm{mg} / \mathrm{dL}, p=0.243)$; however, the percentage of patients with abnormal CRP concentrations was greater in the high-ASDAS group than the lowASDAS group ( $17.8 \%$ vs. $1.4 \%, p=0.001)$.

Initial disease activity indices, including the BASDAI, ASDAS-CRP, and serum concentration of ESR and CRP, were comparable across the two groups. However, patients in the high-ASDAS group still had significantly greater BASDAI scores at 9 months $(2.9 \pm 1.1$ vs. $2.3 \pm$ 1.4, $p=0.007)$ than patients of low-ASDAS group. The mean ASDAS-CRP value and proportion of patients with high ASDAS-CRP assessed at 9 months were greater in patients in the high-ASDAS group, but these results were not statistically significant $(1.8 \pm 0.6$ vs. $1.5 \pm 0.7$, $p=0.079 ; 27.8 \%$ vs. $13.8 \%, p=0.094)$.
A total of 9 patients discontinued anti-TNF treatment due to lack/loss of efficacy, of which 7 cases occurred in the high-ASDAS group and 2 in the low-ASDAS group. All cases of discontinuation due to clinical remission occurred in the low-ASDAS group (Table 2).

\section{Factors associated with high ASDAS-CRP after anti-TNF treatment}

To identify factors associated with a high ASDAS-CRP result after 3 months ( 6 weeks for infliximab) of antiTNF treatment, we used univariable and multivariable logistic regression analyses. Female sex was shown to be a contributor for a high ASDAS-CRP (odds ratio [OR] 5.92, 95\% CI 1.05-33.46, $p=0.044$ ) (Table 3).

\section{Retention rates for anti-TNF agents according to disease activity states}

Kaplan-Meier curves for time to discontinuation due to lack/loss of efficacy for low and high ASDAS group are shown in Fig. 2. The survival of high-ASDAS group patients receiving anti-TNF agents was significantly lower than in those of low ASDAS group (log-rank $p=0.011$ ).

The median time to discontinuation of treatment among patients of the high-ASDAS group was 19.7 (5.5-46.1) months, while the duration of therapy for the 2 cases in the low-ASDAS group who discontinued treatment was 4.9 months and 44.8 months.

\section{Discussion}

In this retrospective cohort study, we found that $38.8 \%$ of patients with low BASDAI scores $(<4)$ after 3 months $(6$ weeks for infliximab) of anti-TNF treatment had high disease activity according to ASDAS-CRP assessment $(\geq 2.1)$. These patients tended to have more severe disease activity after 9 months of anti-TNF treatment and greater risk of discontinuation of anti-TNF treatment than those with low disease activity according to both ASDAS-CRP and BASDAI scores. Female sex was also associated with greater ASDAS-CRP values after 3 months ( 6 weeks for infliximab) of anti-TNF treatment.

There have been few previous studies address in AS disease activity as measured by different assessment systems; however, some studies investigating AS patients treated with anti-TNF agents have provided valuable data. Consistent with our results, one previous study indicated that $36.9 \%$ (210/568 patients) of patients with low BASDAI scores $(<4)$ had high disease activity as measured by the ASDAS-CRP $(\geq 2.1)$ [11]. Moreover, even higher percentages of patients having high ASDASCRP $(\geq 2.1)$ among those having low BASDA score $(<4)$ were shown in two other studies; $62.1 \%$ (64/103 patients) and 65.8\% (48/73 patients) [12, 13].

Assessing more patients into worse conditions cannot be simply judged as better measurement. Interestingly, we 
Table 2 Comparisons of demographic and clinical characteristics between the high-ASDAS and low-ASDAS groups

\begin{tabular}{|c|c|c|c|}
\hline & $\begin{array}{l}\text { High-ASDAS group } \\
(n=45)\end{array}$ & $\begin{array}{l}\text { Low-ASDAS group } \\
(n=71)\end{array}$ & $p$-value \\
\hline Age, years & $35.0(30.2-40.4)$ & $33.1(25.6-40.3)$ & 0.222 \\
\hline Male sex, & $40(88.9)$ & $69(97.2)$ & 0.068 \\
\hline Disease duration, years & $11.1(6.1-15.3)$ & $9.8(4.6-15.8)$ & 0.465 \\
\hline Follow-up duration, years & $6.4(4.0-6.9)$ & $6.5(4.6-7.2)$ & 0.289 \\
\hline HLA B27 positivity & $44(97.8)$ & $71(100)$ & 0.207 \\
\hline Peripheral joint involvement & $22(48.9)$ & $30(42.3)$ & 0.484 \\
\hline History of psoriasis & $1(2.2)$ & $1(1.4)$ & 0.751 \\
\hline History of uveitis & $13(28.9)$ & $22(31.0)$ & 0.811 \\
\hline mSASSS & $12.0(6.0-26.7)$ & $8.0(6.0-23.7)$ & 0.256 \\
\hline BASDAI & $3.0 \pm 0.6$ & $1.8 \pm 0.8$ & $<0.001$ \\
\hline ASDAS-CRP & $2.5 \pm 0.3$ & $1.7 \pm 0.2$ & $<0.001$ \\
\hline $\mathrm{ESR}, \mathrm{mm} / \mathrm{hr}$ & $5.0(2.0-11.5)$ & $2.0(2.0-5.0)$ & 0.003 \\
\hline Abnormal ESR & $7(15.6)$ & $2(2.8)$ & 0.012 \\
\hline $\mathrm{CRP}, \mathrm{mg} / \mathrm{dL}$ & $0.2(0.2-0.3)$ & $0.2(0.2-0.2)$ & 0.243 \\
\hline Abnormal CRP & $8(17.8)$ & $1(1.4)$ & 0.001 \\
\hline Initial BASDAI (0 month) & $6.7 \pm 1.3(n=45)$ & $6.7 \pm 1.5(n=71)$ & 0.768 \\
\hline Initial ASDAS-CRP (0 month) & $3.9 \pm 0.8(n=35)$ & $4.0 \pm 1.0(n=57)$ & 0.471 \\
\hline Initial ESR (0 month), mm/hr & $31.5(17.8-55.0)(n=43)$ & $38.0(21.0-76.0)(n=70)$ & 0.331 \\
\hline Initial CRP (0 month), mg/dL & $1.6(0.9-3.4)(n=43)$ & $1.9(0.2-4.7)(n=70)$ & 0.562 \\
\hline Follow-up BASDAI (9 months) & $2.9 \pm 1.1(n=45)$ & $2.3 \pm 1.4(n=71)$ & 0.007 \\
\hline Follow-up ASDAS-CRP (9 months) & $1.8 \pm 0.6(n=36)$ & $1.5 \pm 0.7(n=58)$ & 0.079 \\
\hline High ASDAS-CRP (9 months) & $10(27.8 \%)$ & $8(13.8 \%)$ & 0.094 \\
\hline Follow-up ESR (9 months), mm/hr & $5.0(2.0-11.0)(n=39)$ & $2.0(2.0-7.0)(n=64)$ & 0.299 \\
\hline Follow-up CRP (9 months), mg/dL & $0.2(0.2-0.2)(n=39)$ & $0.2(0.2-0.2)(n=65)$ & 0.795 \\
\hline Discontinuation of anti-TNF agent & $8(17.8)$ & $5(7.1)$ & 0.022 \\
\hline Lack/loss of efficacy & $7(87.5)$ & $2(40)$ & \\
\hline Clinical remission & $0(0)$ & $3(60)$ & \\
\hline Adverse event & $1(12.5)$ & $0(0)$ & \\
\hline
\end{tabular}

Numerical quantitative data were presented as the "mean $\pm \mathrm{SD}^{\prime}$ or "median (IQR)" and categorical data were presented as the "frequency (\%)"

SD standard deviation, IQR interquartile range, HLA B27 human leukocyte antigen B27, mSASSS modified Stoke Ankylosing Spondylitis Spine Score, BASDAI Bath Ankylosing Spondylitis Disease Activity Index, ASDAS Ankylosing Spondylitis Disease Activity Score, CRP C-reactive protein, ESR erythrocyte sedimentation rate, TNF Tumor necrosis factor

found differences in prognosis between patient groups based on the ASDAS-CRP assessment. Patients with high ASDAS-CRP appeared to have higher disease activity at their follow-up visits despite anti-TNF treatment. Similar results were obtained in previous studies in which the immediate response to the first anti-TNF agent was shown to largely determine the long-term prognosis [14]. In addition, the anti-TNF agent retention rate was significantly lower in AS patients with high ASDAS-CRP results than among patients with low ASDAS-CRP results, although all would be considered to have low disease activity based on their BASDAI score.

"Treat-to-target (T2T)" is a major principle in treating many diseases, such as hypertension, diabetes mellitus, and dyslipidemia. In the past decade, promotion of T2T has spread to inflammatory rheumatic diseases, including rheumatoid arthritis, spondyloarthritis ( $\mathrm{SpA}$ ), systemic lupus erythematosus, and gout [15-18]. After determining the desired target values, the objectives of $\mathrm{T} 2 \mathrm{~T}$ are to ensure accurate and reliable disease assessment and more reasonable treatment decisions (i.e., whether treat or not treat and switch or maintain medications), and to thereby obtain better outcomes. In view of the potential adverse effects and financial burden of anti-TNF treatment, a T2T approach should be emphasised in AS patients treated with anti-TNF agents.

Several attempts have been made to compare the discriminatory capacity of the ASDAS with that of BASDAI 
Table 3 Factors associated with greater assessed ASDAS-CRP after 3 months (12 weeks) of anti-TNF treatment $(n=92)$

\begin{tabular}{|c|c|c|c|c|}
\hline & \multicolumn{2}{|c|}{ Univariable analysis } & \multicolumn{2}{|c|}{ Multivariable analysis } \\
\hline & OR & $p$-value & OR & $p$-value \\
\hline $\operatorname{Age}^{a}$ & $1.26(0.82-1.96)$ & 0.296 & $1.18(0.73-1.90)$ & 0.509 \\
\hline Female sex & $4.31(0.80-23.27)$ & 0.089 & $5.92(1.05-33.46)$ & 0.044 \\
\hline Disease duration ${ }^{\mathrm{b}}$ & $1.18(0.75-1.85)$ & 0.469 & & \\
\hline Initial BASDAI (0 month) & $0.96(0.73-1.26)$ & 0.772 & & \\
\hline Initial ASDAS-CRP (0 month) & $0.85(0.54-1.35)$ & 0.493 & & \\
\hline High mSASSS (> median) & $1.81(0.85-3.85)$ & 0.123 & $1.95(0.85-4.45)$ & 0.113 \\
\hline Peripheral arthritis & $1.31(0.62-2.77)$ & 0.484 & & \\
\hline Uveitis & $0.91(0.40-2.05)$ & 0.811 & & \\
\hline Psoriasis & $1.57(0.10-25.72)$ & 0.753 & & \\
\hline
\end{tabular}

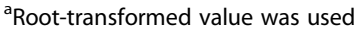

bog-transformed value was used

ASDAS Ankylosing Spondylitis Disease Activity Score, CRP C-reactive protein, TNF tumor necrosis factor, OR odds ratio, BASDAI Bath Ankylosing Spondylitis Disease Activity Index, mSASSS modified Stoke Ankylosing Spondylitis Spine Score

in AS patients treated anti-TNF agents. One previous study investigating eligibility criteria for initiation of anti-TNF treatment in AS patients showed that an ASDAS-CRP result $\geq 2.1$ is associated with a greater likelihood of improvement than a high BASDAI score ( $\geq$ 4), but the patients who had both ASDAS-CRP $\geq 2.1$ and BASDAI $\geq 4$ showed the greatest improvement [12]. Similarly, from another prospective cohort study, applying the ASDAS definition of high disease activity leads to more axial SpA patients being selected to start anti-
TNF treatment and these 'captured' patients have a greater likelihood of known predictors of good response to anti-TNF than traditional BASDAI definition $(\geq 4)$ [13]. One study including patients with AS and undifferentiated SpA treated with etanercept or infliximab revealed that the discriminatory ability of the ASDAS outperformed that of the BASDAI, patient global score, ESR, CRP, or acute inflammation score as assessed by MRI [19]. In addition, a previous study investigating the levels and changes of 10 biomarkers in axial SpA

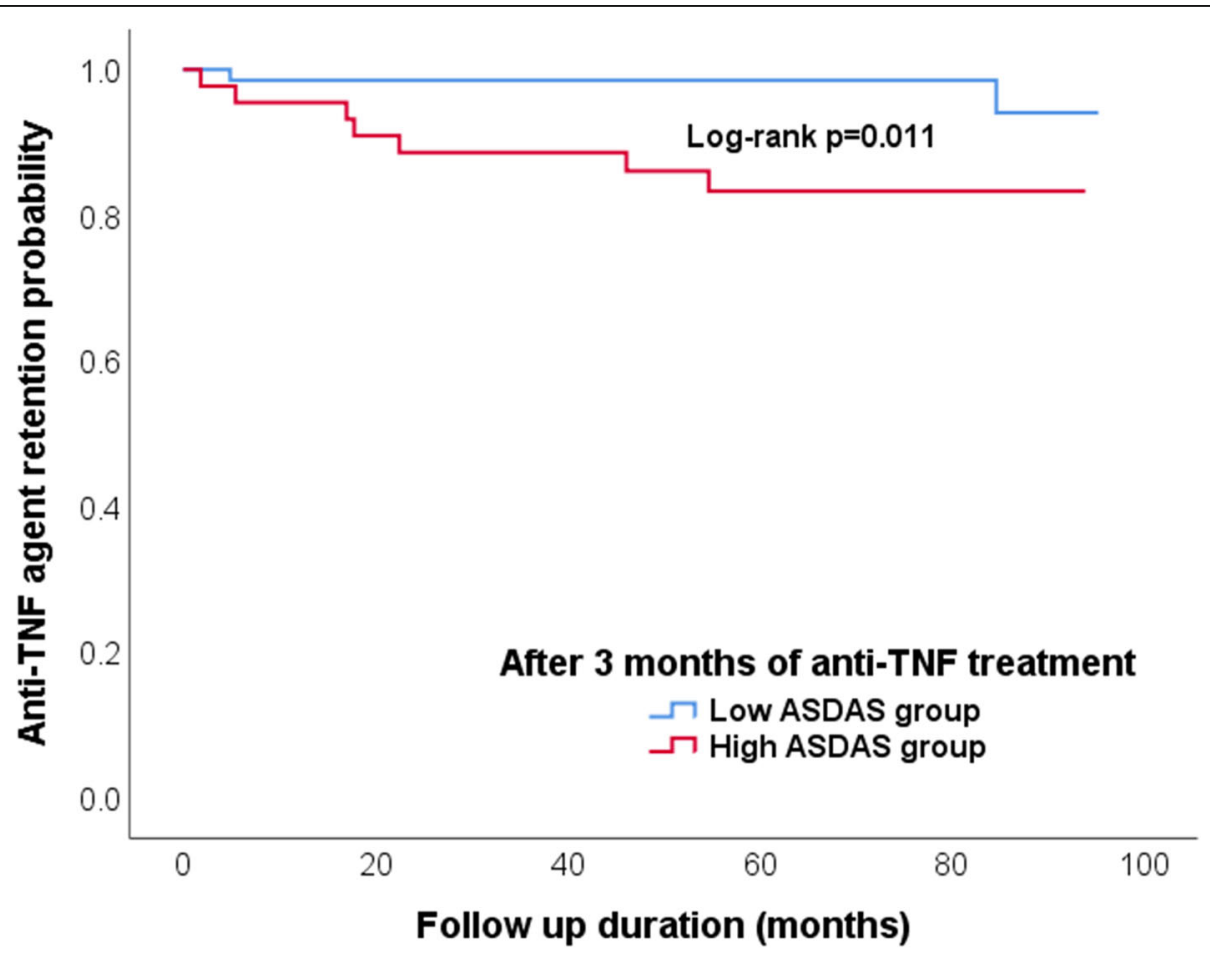

Fig. 2 Comparison of the anti-TNF agent retention rates according to ASDAS-CRP. TNF; tumor necrosis factor; ASDAS, The Ankylosing Spondylitis Disease Activity Score, CRP, C-reactive protein 
patients during anti-TNF treatment revealed that the ASDAS-CRP was more strongly associated with these biomarkers than the BASDAI [20].

Moreover, the ASDAS seems to better predict the patient prognosis than the BASDAI. One prospective study of 2274 AS patients newly treated with anti-TNF agents indicated that a low ASDAS-CRP $(<2.1)$ result after 3 months of anti-TNF treatment predicted the risk of future non-disability better than a low BASDAI $(<4)$ result and low CRP concentration $(<5 \mathrm{mg} / \mathrm{L})$ [14]. A 12-year longitudinal study using data from the OASIS cohort revealed that models including the ASDAS-CRP as the disease activity measure fitted the data better than models including the BASDAI, CRP, or both the BASDAI and CRP. In addition, an increase of one ASDAS-CRP unit led to an increase of $0.72 \mathrm{mSASSS}$ units/2 years [21]. Similarly, in another study from the German SpA inception cohort, radiographic spinal progression was found to be associated with the time-averaged ASDAS-CRP (mSASSS progression by over 2 points/ 2 years: OR 1.80 , 95\% CI 1.04-3.13; syndesmophyte formation/progression: OR 2.45, 95\% CI 1.26 to 4.77) [22]. However, no associations between radiographic progression and BASDAI results have been reported [22, 23].

Female sex was associated with high ASDAS-CRP results after 3 months ( 6 weeks for infliximab) of anti-TNF treatment, which may be attributed to the very small population of female patients in our study population: only five patients were female in the high-ASDAS group, while only 2 patients were female in the low-ASDAS group. On the other hand, several researchers have reported that females were less likely to respond to antiTNF treatment and were more likely to discontinue anti-TNF treatment early based on data from registries of rheumatic disease including AS [24-29]. However, to date, there has been no clear determination of the basis of sex-dependent differences in anti-TNF response and survival, and further study is therefore needed to clarify the relationships between anti-TNF treatment and sex.

The present study has some limitations. First, we only focused ASDAS-CRP although there are available novel activity indices for AS such as the BASDAS formula, similar to the ASDAS-CRP but uses only the BASDAI and CRP, and simplified ASDAS [30, 31]. Measuring ASDAS-CRP is not yet routine in clinical practice. Therefore, the size of our study population was relatively small and selection bias may have occurred due to the retrospective nature of the study; some patients suspected of high disease activity despite of low BASDAI might be assessed with ASDAS-CRP. Second, the number of female patients was small. Therefore, some results need to be interpreted with some caution. It might be explained by relatively high proportion of female patients having high BASDAI $(\geq 4)$ after 3 months of anti-
TNF treatment (12 females among total 61 patients) and consequently being excluded. One of possible explanations of it might be characteristics of female AS patients; several studies have shown that female AS patients tended to report high BASAI score compared to males [32-35]. Or it might be associated to which we suggested in our study; females were less likely to respond to anti-TNF treatment. Third, we only considered disease activity when comparing survival during anti-TNF treatment, and did not consider the type of anti-TNF agent, doses, or dosing intervals in the analyses. Despite these limitations, the present study provides valuable real-world data obtained from AS patients treated antiTNF agents and focused on discordances in disease activity that have rarely been assessed previously. We found a benefit of assessing the ASDAS-CRP with respect to prognosis and drug survival during treatment with anti-TNF agents. Although the applicability of ASDAS-CRP might vary across different regions since the measuring ASDAS-CRP needs laboratory tests and the calculator of digital system [31].

To conclude, a low BASDAI score after anti-TNF treatment may not be as meaningful as previously thought. About $40 \%$ of low-BASDAI patients may have high AS disease activity according to an ASDAS-CRP assessment and be at higher risk of discontinuation of anti-TNF treatment due to lack/loss of effectiveness. In addition, all cases in which anti-TNF treatment was discontinued due to clinical remission were in the lowASDAS group. In consideration of our results and the great capacity of the ASDAS shown in previous studies, we suggest the use of the ASDAS-CRP alone or in addition to the BASDAI when assessing disease activity in AS patients treated with anti-TNF agents.

\section{Acknowledgements}

$\mathrm{NIL}$.

\section{Authors' contributions}

Conceptualization: Nam B, Koo BS, Kim JJ, Kim TH. Data collecting: Nam B, Koo BS, Shin JH, Lee S, Joo KB. Formal analysis: Nam B, Koo BS. Investigation: Nam B, Koo BS. Writing - original draft: Nam B. Writing - review \& editing: Koo BS, Lee TH, Shin JH, Kim JJ, Lee S, Joo KB, Kim TH. The authors read and approved the final manuscript.

\section{Funding}

This research received no specific grants from any funding agency in the public, commercial, or not-for-profit sectors.

\section{Availability of data and materials}

The datasets are available from the corresponding author upon reasonable request.

\section{Ethics approval and consent to participate}

This study was performed according to the guidelines of the Helsinki Declaration and approved by the institutional review board of Hanyang University Hospital (IRB file No. HYUH 2019-09-016). Patient consent to participate was waived as this is a retrospective study. 


\section{Consent for publication}

Not applicable.

\section{Competing interests}

The authors have no conflicts of interest to declare.

\section{Author details}

'Department of Rheumatology, Hanyang University Hospital for Rheumatic Diseases, 222-1 Wangsimni-ro, Seongdong-gu, Seoul 04763, Republic of Korea. ${ }^{2}$ Department of Rheumatology, Inje University Seoul Paik Hospital, Inje University College of Medicine, Seoul, South Korea. ${ }^{3}$ Medical Affairs, AbbVie Ltd., Seoul, South Korea. ${ }^{4}$ Department of Radiology, Hanyang University Hospital for Rheumatic Diseases, Seoul, South Korea.

\section{Received: 5 October 2020 Accepted: 21 December 2020}

\section{Published online: 04 February 2021}

\section{References}

1. Braun J, Sieper J. Ankylosing spondylitis. Lancet. 2007;369:1379-90. https:// doi.org/10.1016/S0140-6736(07)60635-7

2. Smolen JS. Treat-to-target: rationale and strategies. Clin Exp Rheumatol. 2012;30:S2-6.

3. Gupta L, Bhattacharya S, Agarwal V, Aggarwal A. Elevated levels of serum MRP8/14 in ankylosing spondylitis: associated with peripheral arthritis and active disease. Clin Rheumatol. 2016;35:3075-9.

4. Gupta L, Bhattacharya S, Aggarwal A. Tenascin-C, a biomarker of disease activity in early ankylosing spondylitis. Clin Rheumatol. 2018;37:1401-5.

5. Garrett $S$, et al. A new approach to defining disease status in ankylosing spondylitis: the Bath Ankylosing Spondylitis Disease Activity Index. J Rheumatol. 1994:21:2286-91.

6. Lukas C, et al. Development of an ASAS-endorsed disease activity score (ASDAS) in patients with ankylosing spondylitis. Ann Rheum Dis. 2009;68: 18-24. https://doi.org/10.1136/ard.2008.094870

7. Smolen JS, et al. Treating axial spondyloarthritis and peripheral spondyloarthritis, especially psoriatic arthritis, to target: 2017 update of recommendations by an international task force. Ann Rheum Dis. 2018:77: 3-17. https://doi.org/10.1136/annrheumdis-2017-211734.

8. Ward MM, et al. 2019 Update of the American College of Rheumatology/ Spondylitis Association of America/Spondyloarthritis Research and Treatment Network Recommendations for the Treatment of Ankylosing Spondylitis and Nonradiographic Axial Spondyloarthritis. Arthritis Rheumatol. 2019;71:1599-613. https://doi.org/10.1002/art.41042.

9. Lee J-W, et al. Predictors of switching anti-tumor necrosis factor therapy in patients with ankylosing spondylitis. PLoS One. 2015;10:e0131864.

10. van der Linden S, Valkenburg HA, Cats A. Evaluation of diagnostic criteria for ankylosing spondylitis. A proposal for modification of the New York criteria. Arthritis Rheum. 1984;27:361-8. https://doi.org/10.1002/art. 1780270401

11. Vastesaeger $\mathrm{N}$, et al. ASDAS high disease activity versus BASDAl elevation in patients with ankylosing spondylitis as selection criterion for anti-TNF therapy. Reumatol Clin. 2014;10:204-9.

12. Fagerli KM, et al. Selecting patients with ankylosing spondylitis for TNF inhibitor therapy: comparison of ASDAS and BASDAl eligibility criteria. Rheumatology. 2012:51:1479-83.

13. Marona J, et al. Eligibility criteria for biologic disease-modifying antirheumatic drugs in axial spondyloarthritis: going beyond BASDAI. RMD Open. 2020;6:e001145.

14. Tužil J, et al. Short-term response in new users of anti-TNF predicts longterm productivity and non-disability: analysis of Czech ATTRA ankylosing spondylitis biologic registry. Exp Opin Biol Ther. 2020;20:183-92.

15. Smolen JS, et al. Treating rheumatoid arthritis to target: recommendations of an international task force. Ann Rheum Dis. 2010;69:631-7. https://doi. org/10.1136/ard.2009.123919.

16. Smolen JS, et al. Treating spondyloarthritis, including ankylosing spondylitis and psoriatic arthritis, to target: recommendations of an international task force. Ann Rheum Dis. 2014;73:6-16. https://doi.org/10.1136/annrheumdis2013-203419.

17. van Vollenhoven RF, et al. Treat-to-target in systemic lupus erythematosus: recommendations from an international task force. Ann Rheum Dis. 2014;73: 958-67. https://doi.org/10.1136/annrheumdis-2013-205139.
18. Kiltz U, et al. Treat-to-target (T2T) recommendations for gout. Ann Rheum Dis. 2017:76:632-8. https://doi.org/10.1136/annrheumdis-2016-209467.

19. Xu M, et al. The Ankylosing Spondylitis Disease Activity Score is a highly discriminatory measure of disease activity and efficacy following tumour necrosis factor-a inhibitor therapies in ankylosing spondylitis and undifferentiated spondyloarthropathies in China. Rheumatology. 2011;50:1466-72.

20. Pedersen SJ, et al. ASDAS, BASDAl and different treatment responses and their relation to biomarkers of inflammation, cartilage and bone turnover in patients with axial spondyloarthritis treated with TNFa inhibitors. Ann Rheumatic Dis. 2011;70:1375-81.

21. Ramiro $S$, et al. Higher disease activity leads to more structural damage in the spine in ankylosing spondylitis: 12-year longitudinal data from the OASIS cohort. Ann Rheumatic Dis. 2014;73:1455-61.

22. Poddubnyy D, et al. High disease activity according to the Ankylosing Spondylitis Disease Activity Score is associated with accelerated radiographic spinal progression in patients with early axial spondyloarthritis: results from the GErman SPondyloarthritis Inception Cohort. Ann Rheumatic Dis. 2016;75:2114-8

23. Poddubnyy $\mathrm{D}$, et al. Baseline radiographic damage, elevated acute-phase reactant levels, and cigarette smoking status predict spinal radiographic progression in early axial spondylarthritis. Arthritis Rheumatism. 2012;64: 1388-98.

24. Atzeni $F$, et al. Predicting response to anti-TNF treatment in rheumatoid arthritis patients. Autoimmun Rev. 2009;8:431-7.

25. Hyrich K, Watson K, Silman A, Symmons D. Predictors of response to antiTNF-a therapy among patients with rheumatoid arthritis: results from the British Society for Rheumatology Biologics Register. Rheumatology. 2006;45: 1558-65.

26. Lorenzin $\mathrm{M}$, et al. Predictors of response and drug survival in ankylosing spondylitis patients treated with infliximab. BMC Musculoskelet Disord. 2015; 16:166.

27. Glintborg B, et al. Clinical response, drug survival and predictors thereof in 432 ankylosing spondylitis patients after switching tumour necrosis factor a inhibitor therapy: results from the Danish nationwide DANBIO registry. Ann Rheumatic Dis. 2013;72:1149-55.

28. Heiberg MS, et al. The comparative one-year performance of anti-tumor necrosis factor a drugs in patients with rheumatoid arthritis, psoriatic arthritis, and ankylosing spondylitis: results from a longitudinal, observational, multicenter study. Arthritis Care Res. 2008;59:234-40.

29. Glintborg B, et al. Predictors of treatment response and drug continuation in 842 patients with ankylosing spondylitis treated with anti-tumour necrosis factor: results from 8 years' surveillance in the Danish nationwide DANBIO registry. Ann Rheumatic Dis. 2010:69:2002-8.

30. Aranda-Valera IC, et al. How to calculate the ASDAS based on C-reactive protein without individual questions from the BASDAl: the BASDAI-based ASDAS formula. Rheumatology. 2020;59:1545-9.

31. Sundaram T, Muhammed H, Aggarwal A, Gupta L. A prospective study of novel disease activity indices for ankylosing spondylitis. Rheumatol Int. 2020; 40:1843-9.

32. Ibanez Vodnizza SE, van Bentum RE, Valenzuela O, van der Horst-Bruinsma IE. Patients with axial spondyloarthritis report significant differences between men and women and high impact of the disease: Large websurvey analysis. Joint Bone Spine. 2020. https://doi.org/10.1016/j.jbspin 2020.02 .004

33. Rusman T, van Vollenhoven RF, van der Horst-Bruinsma IE. Gender Differences in Axial Spondyloarthritis: Women Are Not So Lucky. Curr Rheumatol Rep. 2018;20:35. https://doi.org/10.1007/s11926-018-0744-2.

34. Yacoub Yl, Amine B, Laatiris A, Hajjaj-Hassouni N. Gender and disease features in Moroccan patients with ankylosing spondylitis. Clin Rheumatol. 2012;31:293-7.

35. Shahlaee A, et al. Gender differences in Iranian patients with ankylosing spondylitis. Clin Rheumatol. 2015:34:285-93.

\section{Publisher's Note}

Springer Nature remains neutral with regard to jurisdictional claims in published maps and institutional affiliations. 